1. FCPS Plastic Surgery

Assistant Professor Plastic Surgery

Rawalpindi Medical University,

Rawalpindi.

2. FCPS Plastic Surgery

Senior Medical Officer

THQ Hospital Sehnsa, Distt. Kotl

AJK.

3. FCPS Plastic Surgery

Assistant Professor Plastic Surgery

Aziz Bhatti Shaheed Hospital,

Gujrat.

4. M.Phil

Assistant Professor Rehabilitation Islamabad Medical and Dental College, Islamabad.

5. FCPS Plastic Surgery

Assistant Professor Plastic Surgery

Bolan Medical College, Quetta.

6. FCPS Plastic Surgery

Assistant Professor Plastic Surgery

D.G Khan Medical College, D.G

Khan.

Correspondence Address:

Dr. Naveed Arshad

Assistant Professor Rehabilitation

Islamabad Medical and Dental

College, Islamabad,

Main Murree Road, Islamabad.

oliajann@gmail.com

Article received on:

13/02/2020

Accepted for publication:

29/05/2020

\section{The consistency of the proximal perforator by using color doppler in anterolateral thigh flap.}

\begin{abstract}
Husnain Khan ${ }^{1}$, Naeem Abbas ${ }^{2}$, Zahid Iqbal Bhatti ${ }^{3}$, Naveed Arshad ${ }^{4}$, Kamaludin Khan ${ }^{5}$,
\end{abstract} Abdul Malik Mujahid ${ }^{6}$

ABSTRACT... Objectives: The objectives of the study are to determine the consistency of the proximal perforator in terms of its presence and location prospectively using preoperative color doppler and per operative confirmation in patients requiring anterolateral thigh flap. Study Design: Descriptive Case Series. Setting: Department of Plastic Surgery at Jinnah Hospital Lahore. Period: From April 2017 to October 2017. Material \& Methods: A total of 60 patients requiring anterolateral thigh flap were recruited for the study. Consistency of the proximal anterolateral thigh flap perforator was labeled if AK/AP $\leq 0.45$. Findings were confirmed per operatively. Results: Presence of proximal perforator was consistent in 51 (85\%) individuals with mode of 0.42 (AK/AP ratio) $\pm 0.04 \mathrm{~cm}$ SD. Similarly per operative presence of the proximal perforator was consistent in 54 (90\%) individuals with mode of 0.42 (AK/AP ratio) $\pm 0.04 \mathrm{~cm}$ SD. Conclusion: Proximal perforator is highly consistent in its presence and place in our population requiring anterolateral thigh flap.

Key words: Anterolateral, Color Doppler Ultrasonography, Flap, Proximal, Perforator, Thigh.

Article Citation: Khan H, Abbas N, Bhatti ZI, Arshad N, Khan K, Mujahid AM. The consistency of the proximal perforator by using Color Doppler in anterolateral thigh flap. Professional Med J 2020; 27(11):2320-2325.

https://doi.org/10.29309/TPMJ/2020.27.11.4569

\section{INTRODUCTION}

The anterolateral thigh flap was initially described by Song in $1984 .^{1}$ It was introduced in Asia and has gained international popularity because of a recent shift toward perforator flaps. Advances in the past century that have made perforator free flaps possible include anatomical works, improvements in operative microscopy, and refinements in surgical techniques. It is one of the most versatile ${ }^{2}$ flaps especially when used as a free flap for head and neck reconstruction, extremity defects ${ }^{3}$, and as a pedicled flap for Phalloplasty, lower abdominal wall defects and trochanteric defects with minimum donor site morbidity. ${ }^{4-7}$ It is used as fascio-cutaneous as well as musculo-cutaneous along with the cuff of vastus lateralis muscle. Tissue expansion is also possible prior to flap elevation to increase both the fascial and cutaneous territory and to expedite donor site closure.

Scopus P Yu in 2004 classified the perforators supplying this area as $\mathrm{A}$ (proximal), $\mathrm{B}$ (middle) and C (distal) perforators based on 72 Anterolateral thigh flaps' exploration. ${ }^{8}$ The middle perforator (B) is well known for flap elevation, which is intramuscular in more than $80 \%$ of cases. ${ }^{2}$ In general, the proximal perforators have larger chance to be septo-cutaneous, and the distal perforators usually are musculo-cutaneous in majority. ${ }^{9}$ A study done by Mateusz Zachara 140 perforators were identified in 60 Anterolateral thighs flaps. He found 55 (92\%) flaps having the proximal (A) perforator. ${ }^{10}$ In older studies as Kimata $^{11}$ in 1998 and $\mathrm{Yu}^{8} 2004$ it was 64\% and $49 \%$ respectively.

The harvest of anterolateral thigh flap based on the proximal perforator $(A)$ is very simple and quick because of its superficial and septocutaneous course while the harvest of flap based on middle perforator $(B)$ is quite difficult because of its musculo-cutaneous course with increased risk of complications. ${ }^{12}$ Preoperative mapping of 
perforators performed by handheld doppler. Color Doppler ultrasound and angiography has been used. Angiography is an invasive procedure and not without hazards. ${ }^{13,14}$ For preoperative marking of perforators handheld doppler is commonly used. However, there are many advantages of color doppler ultrasound (CDU) over handheld doppler. Studies showed that CDU is more precise and reliable to detect perforating vessels of the anterolateral thigh flap than handheld doppler. ${ }^{15,16}$ Visualization of perforator passage through the fascia could be done with CDU, which cannot be possible with handheld doppler. Furthermore, in some instances, the handheld doppler mistook feeding vessels falsely as being perforators. Some researchers found that handheld doppler mistakenly pick feeding vessels. ${ }^{17}$

There is no study on national level, as far our knowledge, on consistency of the proximal anterolateral thigh flap perforator and the studies conducted at international level are mostly retrospective review studies, with significant result variations. We did this study to assess the consistency of this perforator $(A)$ in terms of its presence and location in our population using preoperative color doppler and also its confirmation per operatively, during anterolateral thigh flap harvest, prospectively.

\section{MATERIAL \& METHODS}

This study was a descriptive case series conducted at plastic surgery department Jinnah Hospital Lahore, from April 2017 to October 2017. Total 60 patients were inducted in the study with confidence level of $95 \%$, acceptable difference of $8 \%$ and assumed proportion of proximal perforator $92 \% .{ }^{10}$ Patients with age range 10 to 55 years, of both genders undergoing anterolateral thigh perforator flap for any reason were included in the study. Non-probability convenience sampling was used to pick the patients. Patients with congenital malformations determined on history and clinical examination, having diabetes mellitus determined on history and laboratory tests and unfit for prolonged anesthesia as determined by Anesthetist were excluded from the study. An informed consent was taken for color doppler, operation and to gather information for study.
A line was drawn from anterior superior iliac spine to the supero-lateral border of the patella. The length of this line (AK distance) was recorded. A circle of radius of $1 / 20$ th of the total length of this line was drawn at midpoint of this line. The doppler signals were marked using handheld doppler on this line proximal to this circle and within this circle as shown in Figure-1. After marking with handheld doppler, the color doppler scan was used for marking of the perforator as shown in Figure-2. After marking following assessments were noted.

AP distance: The distance in centimeters between anterior superior iliac spine (ASIS) to the perforator as determined by color doppler mapping and per operatively was marked as AP distance. AP ratio is the ratio of AP distance to AK distance.

Proximal perforator: The perforator with AP ratio $\leq 0.45$ was labeled as proximal perforator as already classified by Scopus $\mathrm{P} Y u .{ }^{8}$ Consistency in terms of presence: was the percentage of thighs having proximal perforator noted per operatively.

Consistency in terms of location: is the most commonly occurring location and was measured as Mode \pm SD of AP ratios of proximal perforators. All these markings were entered on a performa.

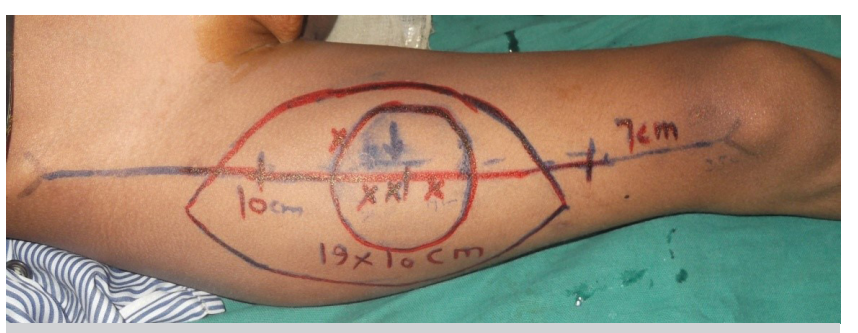

Figure-1. Marking and mapping

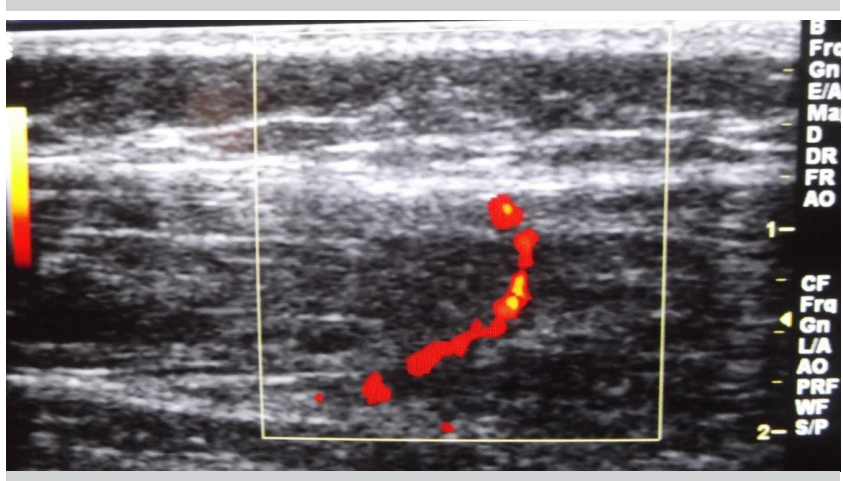

Figure-2. Color doppler mapping 
The anterolateral thigh flap was raised as standard teachings in text book of plastic surgery third edition 2013 Peter C. Neligan. ${ }^{18}$ The descending branch and its perforators were identified. The short oblique branch or proximal perforator that inserts at the terminal insertion of the tensor fasciae latae muscle was also identified. The distance was measured from ASIS to the location of perforator.

Data was entered and analyzed in SPSS version 19.0. Mean and standard deviation was calculated for quantitative variables like age, AK, AP distance, and AP ratio. The qualitative data like gender, consistency of perforator with reference to presence was presented as frequency and percentage. Dependent variable i.e. proximal perforator presence was done with gender and chi square $\left(X^{2}\right)$ test was used to assess the statistical significance. Mean age was compared using independent sample $t$ test while post stratification chi square test was used. $P$ value $\leq$ 0.05 was taken as significant.

\section{RESULTS}

Total sixty (60) patients according to inclusion criteria were enrolled in the study after informed consent. Out of 60 patients, 48 (80\%) were male while 12 (20\%) were female with mean age $26.67 \pm 5.20$ years, minimum 11 years and maximum 55 years. When we used doppler in our sampled population in the presence of the proximal perforator was present in 51 (85\%) individuals while there was non-consistent presence of proximal perforator in 9 (15\%).

Per operative examination showed more consistency regarding presence of the proximal perforator i.e. $54(90 \%)$ patients had the proximal perforator while 6 (10\%) don't have it within $0.45 \mathrm{AK} / \mathrm{AP}$ ratio. Mean AK distance of included patients was $46.5 \pm 4.6 \mathrm{~cm}$ ranging from $36 \mathrm{~cm}$ to $58 \mathrm{~cm}$ while AP distance of doppler was $18.8 \pm 2.1 \mathrm{~cm}$ ranging from $14 \mathrm{~cm}$ to $24 \mathrm{~cm}$ while AP distance preoperative was $14 \mathrm{~cm}$ to $24 \mathrm{~cm}$ and mean was similar for both Per operative and doppler assessment i.e. $18.84 \pm 2.185 \mathrm{~cm}$.

Among 60 patients, AK/AP ratio both by doppler and per operative examination was $0.40 \pm 0.04$ ranging from 0.33 to 0.45 with a modal distribution of 0.42 .

\begin{tabular}{|l|l|c|c|c|c|}
\hline \multicolumn{5}{|c|}{ Consistency of the proximal perforator by Doppler } \\
\hline \multirow{2}{*}{ Sex } & No & Yes & Total & P-Value \\
\cline { 2 - 6 } & Female & 5 & 43 & 48 & \\
\hline \multirow{2}{*}{ Total } & 4 & 8 & 12 & 0.069 \\
\hline
\end{tabular}

\begin{tabular}{|c|c|c|c|c|c|}
\hline \multicolumn{6}{|c|}{ Per operative consistency of the proximal perforator } \\
\hline \multirow{2}{*}{ Sex } & Male & 2 & 46 & 48 & \multirow{3}{*}{0.012} \\
\hline & Female & 4 & 8 & 12 & \\
\hline \multicolumn{2}{|l|}{ Total } & 6 & 54 & 60 & \\
\hline \multicolumn{6}{|c|}{$\begin{array}{c}\text { Table-I. Statistical analysis between sex, the consisten } \\
\text { presence of the proximal perforator by doppler \& per } \\
\text { operative consistency }\end{array}$} \\
\hline
\end{tabular}

Chi square distribution was used and $p$ values are shown. There was a non-significant difference between male and female regarding the consistency of the presence of proximal perforator by doppler $(p$-value $=0.069)$ showing that doppler is highly sensitive both in male and female to determine the position and location of the proximal perforator. Meanwhile on per operative finding we found a trend towards more change in there was significant difference between male and female in the proximal perforator per operative $(p$-value $=0.012)$ that doppler is less specific to determine the position and location of the proximal perforator in female and also female are less consistent for the presence of the proximal perforator.

\begin{tabular}{|c|c|c|c|c|c|c|}
\hline \multicolumn{7}{|c|}{ Consistency of the proximal perforator by Doppler } \\
\hline & & $\mathbf{N}$ & Mean & SD & $\begin{array}{l}\text { Std. Error } \\
\text { Mean }\end{array}$ & P-value \\
\hline \multirow{2}{*}{$\begin{array}{l}\text { Age in } \\
\text { Years }\end{array}$} & No & 9 & 24.78 & 17.634 & 5.878 & \multirow{2}{*}{0.689} \\
\hline & Yes & 51 & 27.00 & 14.898 & 2.086 & \\
\hline \multicolumn{7}{|c|}{ Consistency of the proximal perforator per operative } \\
\hline \multirow{2}{*}{$\begin{array}{l}\text { Age in } \\
\text { Years }\end{array}$} & No & 6 & 31.67 & 18.074 & 7.379 & \multirow{2}{*}{0.4} \\
\hline & Yes & 54 & 26.11 & 14.936 & 2.033 & \\
\hline \multicolumn{7}{|c|}{$\begin{array}{l}\text { Table-II. Mean age effects on the consistent presence } \\
\text { of the proximal perforator by doppler \& per operative } \\
\text { consistency }\end{array}$} \\
\hline
\end{tabular}


Equal variances assumed, using independent samples t test, $p$-values are shown. Mean age was equally distributed in both age groups consistence and non-consistence proximal perforator by doppler. Similarly mean age was similar preoperatively in both groups ( $p$-value $=0.4)$ i.e. not effecting the consistency.

\section{Representative Cases}

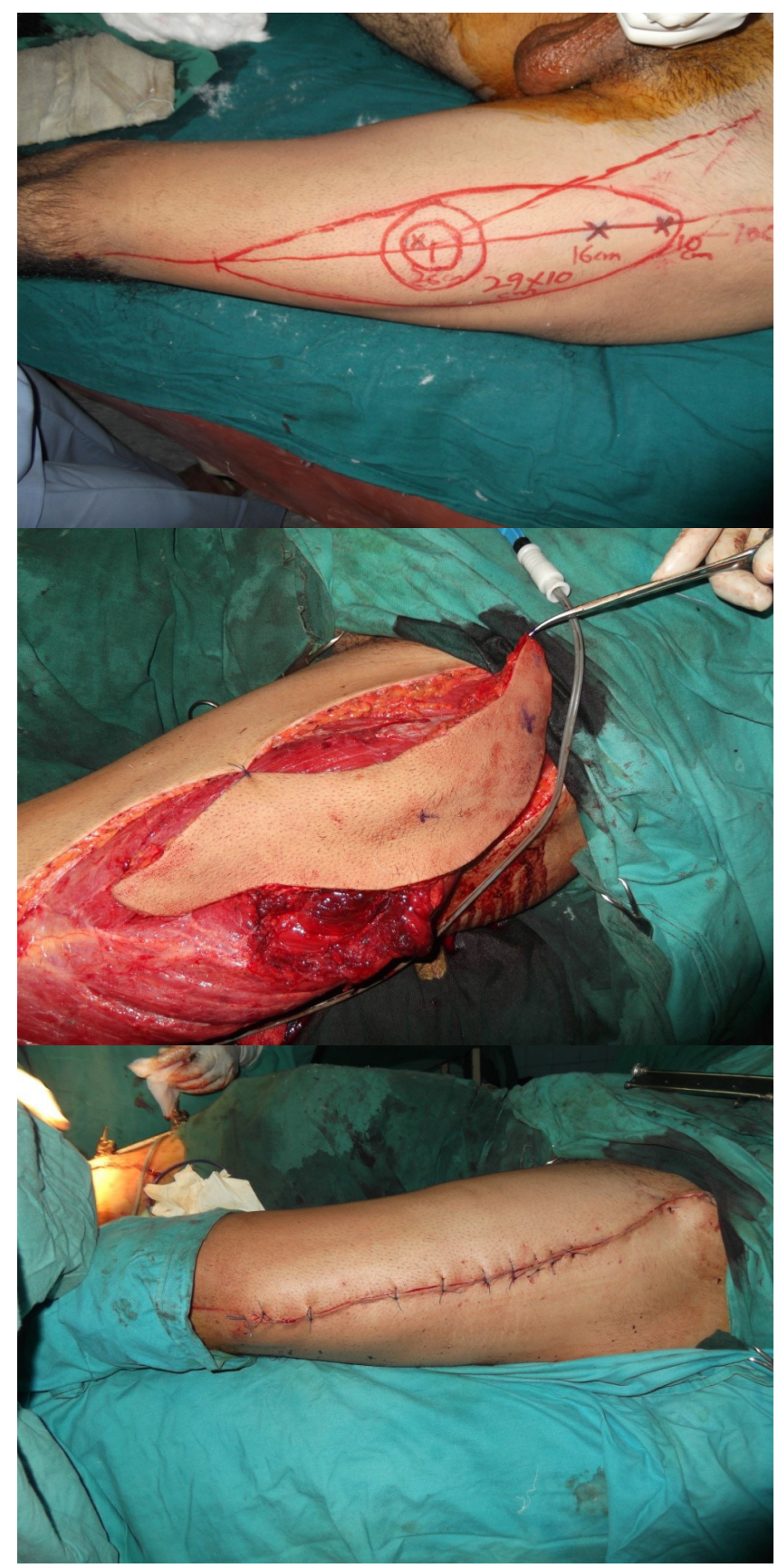

\section{DISCUSSION}

The age of our included patients ranged from
11 to 55 years showing all age groups need the anterolateral thigh flap for different reasons. Mean age was 26.6 years showing increase need of plastic surgery procedures in young age. Disease burden in such cases lead to better outcome and knowing the normal anatomy of different perforators needed for the anterolateral thigh flap is essential.

Most of the patients included our study were male. This may be due to the difference of the health seeking behavior of our target population. Few female (20\%) presented to our department during study period. The consistent presence of the proximal perforator as assessed by doppler was found in $85 \%$ patients i.e. $85 \%$ of patients has AP over AK ratio within 0.45 . It is larger than reported by Kamita et $\mathrm{al}^{11}$ and $\mathrm{Yu}$ et al. $^{8}$ who have reported it $64 \%$ and $49 \%$ respectively.

Hand held doppler has shown high sensitivity (no false negative) regarding the determination of the presence of the proximal perforator by doppler in both male and female but somewhat less specificity in female. Similarly when we compared these results with per operative finding we found $90 \%$ of the patients had the proximal perforator within our operationally defined area i.e. its consistency was $90 \%$ by presence. We determined the mean, mode and standard deviation for sampled population by distances. $\mathrm{AK}$ and $\mathrm{AP}$ ratio was ranged 0.33 to 0.45 with mean of $0.40 \pm 0.04$ by doppler and $0.40 \pm 0.03$ per operatively. The mode was 0.42 almost covering 12 subjects by doppler and 13 by per operative findings.

When compared gender with the consistent presence of the proximal perforator by doppler there was a non-significant difference showing that doppler is efficacious to rule out the effect of gender but per operative findings were quite different there was a trend of more nonconsistency in female. When we applied chi square test $(p-$ value $=0.012)$ it was significant. Mean age had no effect showing that we can easily use this parameter to determine the presence of the proximal perforator of the anterolateral thigh flap in all age groups. 


\section{CONCLUSION}

It is concluded that in our target population, patients have consistent presence of the proximal perforator by per operative findings. Proximal perforator is highly consistent in its presence and place in our population requiring anterolateral thigh flap.

Copyright@ 29 May, 2020.

\section{REFERENCES}

1 .Song YG, Chen GZ, Song YL. The free thigh flap: A new free flap concept based on the septocutaneous artery. Br J Plast Surg. 1984; 37:149-159.

2. Ali RS, Bluebond-Langner R, Rodriguez ED, Cheng MH. The versatility of the anterolateral thigh flap. Plast Reconstr Surg 2009; 124:e395-e407.

3 .Saint-Cyr M, Schaverien M, Wong C. The extended anterolateral thigh flap: Anatomical basis and clinical experience. PlastReconstr Surg2009; 123:1245-1255.

4. Rashid M, Aslam A, Malik S, Tamimy MS, Ehteshamul-Haq et al. Clinical applications of the pedicled anterolateral thigh flap in penile reconstruction. $J$ Plast Reconstr Aesthetic Surg 2011; 64:1075 -1081.

5. Amin MM, Javed L, Sajid M. Penile reconstruction in severe injury: Phalloplasty with an island anterolateral thigh flap (ALTF). Pak J Plast 2012; 1(1):10-16.

6. Garaffa G, Antonini G, Gentile V, Ralph DJ. Phalloplasty for the genetic male. Transl Androl Urol 2012; 1(2):103108.

7. Tzeng YS, Yu CC, Chou TD, Tim MM, Chen SG. Proximal Pedicled Anterolateral Thigh Flap for Reconstruction of Trochanteric Defect. Ann Plast Surg 2008; 61(1):7982.

8. Yu P. Characteristics of the anterolateral thigh flap in a Western population and its application in head and neck reconstruction. Head Neck 2004; 26:759-769.
9. Lee YC, Chiu HY, Shieh SJ. The Clinical Application of Anterolateral Thigh Flap. psi(127353).2011(cited 2012 Dec 19);2011:(5 p). Available from:www.hindawi. com/journals/psi/2011/127353/ref/. Last accessed 12, November 2013.

10. Zachara M, Drozdowski P, Wysocki M, Siewiera I, Wójcicki P. Anatomical variability of the anterolateral thigh flap perforators between sexes: a cadaveric study. Eur J Plast Surg 2013; 36:179-184.

11. Kimata $\mathrm{Y}$, Uchiyama K, Ebihara S, Nakatsuka T, Harii K. Anatomic variations and technical problems of the anterolateral thigh flap: A report of $\mathbf{7 4}$ cases. Plast Reconstr Surg.1998; 102:1517-1523.

12. Saint-Cyr M, Oni G, Lee M, Yi C, M. Colohon S. Simple approach to Harvest the Anterolateral Thigh Flap. Plast Reconstr Surg 2012; 129(1):207-211.

13. Otsuki Y, Yamada K, Hasegawa K, Kimata Y. Evaluation of Diagnostic Accuracy Using Preoperative Handheld Doppler in Identifying the Cutaneous Perforators in the Anterolateral Thigh Flap. Plast Reconstr Surg 2012; 129(4): 770-770e.

14. Jethan HJ. Colour doppler assessment of the perforators of anterolateral thigh flap and its usefulness in preoperative planning. Pol Przegl Chir 2012; 84(3):119-125.

15. Lethaus B, Loberg C, Kloss-Brandstätter A, Bartella AK, Steiner T, Modabber A, Hölzle F, Teichmann J. Color duplex ultrasonography versus handheld Doppler to plan anterior lateral thigh flaps. Microsurgery. 2017; 37:388-393.

16. Cheng H-T, Lin F-Y, Chang SC-N. Diagnostic efficacy of color Doppler ultrasonography in preoperative assessment of anterolateral thigh flap cutaneous perforators: an evidence-based review. Plast Reconstr Surg. 2013; 131:471e-473e.

17. Nanno M, Kodera N, Tomori Y, Hagiwara Y, Takai S. Color Doppler ultrasound assessment for identifying perforator arteries of the second dorsal metacarpal flap. J Orthop Surg. 2017; 25:230949901668474.

18. Neligan P. Plastic surgery. London: Elsevier Saunders; 2013. eBook ISBN-9781455740499. 


\begin{tabular}{|c|c|c|c|}
\hline \multicolumn{4}{|c|}{ AUTHORSHIP AND CONTRIBUTION DECLARATION } \\
\hline Sr. \# & Author(s) Full Name & Contribution to the paper & Author(s) Signature \\
\hline 1 & Husnain Khan & $\begin{array}{l}\text { Conception, design, Synthesis and Planning } \\
\text { of the research, Active participation in data } \\
\text { collection and management, drafting of } \\
\text { article. }\end{array}$ & $n$ \\
\hline 2 & Naeem Abbas & $\begin{array}{l}\text { Participation in active methodology, } \\
\text { Assembly of data, Statistical expertise. }\end{array}$ & Ablos \\
\hline 3 & Zahid Iqbal Bhatti & $\begin{array}{l}\text { Critical revision of the article for important } \\
\text { intellectual content. }\end{array}$ & Sobater \\
\hline 4 & Naveed Arshad & $\begin{array}{l}\text { Analysis and interpretation of the data and } \\
\text { drafting. }\end{array}$ & $Q$ \\
\hline 5 & Kamaludin Khan & $\begin{array}{l}\text { Participation in statistical analysis and } \\
\text { drafting. }\end{array}$ & than \\
\hline 6 & Abdul Malik Mujahid & Active participation in discussion. & Meyahid \\
\hline
\end{tabular}

